\title{
Operating Room Effectiveness: a Lean Healthcare Performance Indicator
}

\begin{tabular}{|r|l|}
\hline Journal: & International Journal of Lean Six Sigma \\
\hline Manuscript ID & IJLSS-12-2017-0141.R3 \\
\hline Manuscript Type: & Research Paper \\
\hline Keywords: & $\begin{array}{l}\text { Operating Rooms, Lean Healthcare, Key performance indicator, Overall } \\
\text { Equipment Effectiveness, Hospitals Operations Management }\end{array}$ \\
\hline \multicolumn{2}{|l}{} \\
\end{tabular}

\section{SCHOLARONE \\ Manuscripts}

Souza, T. A., Vaccaro, G. L., \& Lima, R. M. (2020). Operating room effectiveness: a lean health-care performance indicator. International Journal of Lean Six Sigma. doi:10.1108/IJLSS-12-2017-0141

\section{(ㅇ)(1) (2)}

Attribution-NonCommercial 4.0

International (CC BY-NC 4.0) 


\section{Operating Room Effectiveness: a Lean Healthcare Performance Indicator}

Purpose - Overall Equipment Effectiveness (OEE) is a performance indicator that is been used to measure manufacturing productivity. This paper proposes the Operating Room Effectiveness (ORE) for Hospital Operating Rooms, adapted from the OEE, to measure performance and identify losses based on Lean Healthcare principles.

Methodology - The present study is an exploratory, descriptive, and applied research work. Literature review, documents of the Hospital, observation and interviews with employees of a large university hospital in southern Brazil were analyzed to organize the proposed effectiveness indicator. After that, historical data of the Operating Rooms was collected and the usefulness of the indicator was analyzed. The indicator was applied for 10 months and validated with an expert committee from the hospital.

Findings - The present study describe an adaptation of a performance indicator to operating rooms of hospitals, allowing to classify its types of operational losses in a Lean Healthcare context. The application of this indicator and the development of improvement actions to an university hospital, resulted in operational efficiency gains of $12 \%$ and estimated annual savings of US $\$ 400,000$.

Practical implications - Operating rooms are a critical service for hospitals. This paper presents a new way to measure the performance of operating rooms and identify their main types of wastes. It also shows how to implement it and the potential gains of its application. The main research limitations are related to technical analysis of care data from doctors and nurses involved.

Originality - This paper fulfils the need to study how operating rooms performance can be measured and its operational wastes can be identified. In addition, this paper classifies the planning, performance and quality related losses, which can be used by researchers and practitioners to improve the performance of operation rooms.

Keywords: Hospitals Operations Management, Operating Rooms, Lean Healthcare, Key Performance Indicator, Overall Equipment Effectiveness. 


\section{INTRODUCTION}

In the field of Operations Management, the analysis of production systems is based on assumptions about the relationship between the system's capacity and demand. The context of health services, especially in public systems, is typically characterized by significantly greater demand than supply (Graban, 2009). Furthermore, in many cases, demand has an upward trend, with no compatible increase in capacity. As a natural consequence, increasing the system's output requires effective and focused management processes to increase the system's efficiency and effectiveness (Hopp and Spearman, 2011). Given this context and given that overall healthcare costs, health systems are increasingly challenged to deliver better people care by using fewer resources, thus improving operational effectiveness and efficiency and reducing wastes.

In this context, a unit of particular interest in hospital management is the operating room (OR). Accounting for a substantial portion of the hospital's revenues and costs (Demeulemeester et al., 2013), the OR is a production structure that has a linear flow that typically consists of preparation, operation, and post-operation. Capacity is nominally limited to the number of available operating rooms, equipment, and personnel and to technical delays, administrative aspects, and other factors (Cima, 2011). An OR with underutilized capacity, in a context of increasing demand for surgery, will result in a scenario characterized by long lines and waits, in addition to patient dissatisfaction and the deterioration of the patient's condition. In some cases, clinical complications due to waiting for surgery can change the established demand for the OR by changing the procedures necessary to restore the patient's health.

The newly admitted patient in the OR represents an elective demand or an urgent demand. Urgencies can be further classified as critical (emergency) or non-critical (Cardoen et al., 2010). Managing the capacity of this type of demand requires careful study and the controlled maintenance of capacity, given the impossibility of controlling urgent demands and emergencies in particular. Therefore, the context of health and criticality imposes restrictions on maximizing the efficiency of this production system, unlike what is typically found in an industrial process. Nonetheless, the context is similar to the programmed inefficiency concept used in the Toyota Production System (Shingo, 1989). However, considering the importance of healthcare and the financial impact on the operation of a healthcare service provider, optimizing the outcome of this unit must be a priority of the health organization's management.

From the healthcare management perspective, there has been progress. In recent decades, technological developments have played an important role in the development of 
surgery and have caused substantial changes in the working conditions in the OR. The growing number of complex devices leads to an increase in interactions between humans and technology (Matern and Koneczny, 2007), requiring the adaptation of the layout of operating rooms, in addition to investments in equipment that do not necessarily replace the existing equipment (Graban, 2009). However, the lack of visibility of the most effective actions, from the managerial perspective, can impede the possibility of increasing the OR's performance.

In Brazil, the professionalization of health management processes has not followed the trajectory of healthcare processes. The end goals of clinical protocols, high-tech equipment, and costs and resources that represent annual investments of approximately $9 \%$ of the Brazilian GDP (OECD, 2014) are limited or frustrated by the inadequacy or low efficiency of the management processes associated with these issues. Studies that highlight this fact emphasize the need for professional management based on advanced management techniques in a hospital organization due to its complexity, management problems, financial constraints, and the need for efficiency and quality in healthcare processes (Ribeiro, 1993). In response, management methods emerge in Brazil and abroad that seek to reduce costs, increase efficiency, and solve healthcare services through new structures and management processes (Spagnol and Ferraz, 2002; Graban, 2009).

An alternative to addressing the managerial issues associated with production efficiency is the Lean Healthcare approach (Young and McClean, 2008; Narayanamurthy et al., 2018). Derived from traditional lean thinking and adapted to the health management context (Raval, Kant \& Shankar, 2018), this approach aims to increase the productivity of the processes through the elimination of waste, in addition to operations management techniques aimed at raising efficiency rates (Womack and Jones, 2010). The term "lean" was originally coined to describe a system that could achieve the same output by using lower number of resources - physical space, work effort, capital investment, and inventory - and generating less defects and safety incidents. Over time, the term has also come to mean a method for obtaining such results (Graban, 2009). Bakar, Subari and Daril (2015) studied critical success factors for application of improvement techniques such as Lean and Six Sigma, as well as their integration. The authors demonstrate that Lean's primary goal in organizations is to improve the process flow, reducing waste, non-value added work and cycle time.

Despite its recentness, Lean Healthcare shows results. A multidisciplinary task force conducted a study that applied lean thinking in an ear, nose, and throat (ENT) operating room in the University of Michigan health system. After 18 months, the study reported improvements in process efficiency and staff morale, which was supported by the education of residents, and 
financial gains of approximately $\$ 330,000$ were generated. The study projected an estimated increase of 6,500 hours in service capacity per year based on the process's replication in other operating rooms (Collar, 2012). In Brazil, a hospital in the interior of São Paulo applied techniques from Lean Healthcare to study the flow of surgical patients, in turn applying Value Stream Mapping for the process design. It was observed that the hospital in question was able to increase surgical production by $34 \%$ through the greater use of rooms and reduced set-up for cleaning and changing rooms (Morilhas et al., 2013). However, efficiency or effectiveness indicators in operating rooms are restricted to the analysis of only one variable at a time, such as utilization, production, cancellations, or financial results, and they are not a global indicator that signals the time used and respective losses in the process.

A search applied in Scopus and in Web of Knowledge databases did not produce a single result, in articles published in journals, about Overall Equipment Effectiveness (OEE) applied in Lean Healthcare. The present study aims to fill this research gap, presenting an adaptation of the Overall Equipment Effectiveness (OEE) indicator to operating rooms. This research led to the proposal for a new nomenclature of the indicator focused on operating rooms, Operating Room Effectiveness (ORE). The development of this indicator was based on a study conducted in a large Brazilian university hospital responsible for performing approximately 7,000 operations per year. From the practice perspective, the incorporation of the proposed effectiveness indicator in the OR create a measurement indicator focused on the productivity and quality of the operating rooms, showing the types and dimension of operational wastes. This approach also contributes to theory, to the extent that it encourages a more comprehensive discussion of the performance indicators related to operating rooms, creating a systemic concept of performance for ORs, including the identification of type of losses related to planning, performance and quality. Thus, it opens a way to identify opportunities for improving operational effectiveness in in the hospital and health environment. In summary, the adaptation of OEE, an indicator commonly used in manufacturing systems to a hospital environment, contributes for the reduction of a gap related to operational measurement in hospitals, more precisely in the surgical services. The application of the proposed indicator in a specific OR unit and the resulting actions geared toward process improvement, produced an operational gain of $12 \%$ in the efficiency of the operating rooms studied. Waste has been lifted and a robust action plan to mitigate them has been implemented by the hospital's management team resulting in estimated savings of US $\$ 388,000$ per year.

The paper is structured in six main parts. After this introduction (1), a review about “Operating Rooms Performance Measurement" (2) is presented. After that, the paper presents 
the methodology (3) used in this work. Section 4 presents the "Operating Room Effectiveness (ORE)" indicator. Section 5 describes an application of the indicator and the analysis of the results. Finally, the paper ends with final considerations (6) to the work developed.

\section{OPERATING ROOMS PERFORMANCE MEASUREMENT}

Operating Rooms are important contributors to patient turnover and the financial sustainability of a hospital (Cima, 2011; Dexter et al., 2003; Marjamaa et al., 2008). However, they also represent one of the costliest units. As the economic environment for healthcare providers becomes increasingly challenging, increasing the productivity of the operating room must be guided by the impact on the patient, the safety of personnel, and the results. Several factors limit the productivity of operating rooms, such as infrastructure, human resource management, scheduling dynamics, process flow, technology issues, and limitations in information management. The following are factors that impede the achievement of high performance in ORs: variability in patient problems; the variety of types of interventions; unexpected events that occur in any surgical practice (Cima, 2011); and ineffective process management that permeates the industry, such as the ineffective control of operating time, low efficiency in room cleaning and preparation, weaknesses in inventory control and material handling, and the ineffective management of queues. Continuously improving the efficiency and effectiveness of ORs is manifested by the reduction in operating times; the training of doctors, residents, and other employees; the choice of anesthesia; efficient scheduling; and monitoring the overall performance of the operating rooms. The combination of actions such as those listed above is important for continuous improvement and the achievement of the objectives of a health system. When designing processes or changes, clear targets should be established, and the results achieved must be monitored and communicated to everyone involved (Marjamaa et al., 2008).

Various performance criteria can be used to assess the planning of operating rooms and scheduling procedures. Eight performance measures can be analyzed in this context, namely, waiting time, throughput, utilization, leveling, makespan, patient cancellations, financial results, and preferences, as described in Table 1 (Demeulemeester et al., 2013). These criteria summarize the indicators used in operating room management, as shown in the literature, and they quantitatively represent various stages of the surgical process, from the patient waiting time to the time used for planning, cancellations of surgery, and even financial results, such as the operating room's income and expenses. 
Table 1 - Performance Measures. Adapted from Demeulemeester et al. (2013)

\begin{tabular}{|c|l|}
\hline Performance Measures & \multicolumn{1}{c|}{ Description } \\
\hline Waiting time & $\begin{array}{l}\text { Represents the patient waiting time from the identification of surgical } \\
\text { needs to completion. }\end{array}$ \\
\hline Throughput & $\begin{array}{l}\text { Measurement related to the patient and waiting time, such that the } \\
\text { greater the yield of the operating rooms is, the shorter the patient waiting } \\
\text { time. }\end{array}$ \\
\hline Use & $\begin{array}{l}\text { Indicator related to the time spent using the operating room compared to } \\
\text { the scheduled time. The use does not take into account stops for } \\
\text { preparation and cleaning the rooms or scheduled stops. It only accounts } \\
\text { for the time used in relation to the time scheduled for production. }\end{array}$ \\
\hline Leveling & $\begin{array}{l}\text { Leveling concerns the development of operating room schedules that } \\
\text { lead to the smooth occupation of resources, without peaks and } \\
\text { minimizing the risk of capacity problems caused by unexpected events. }\end{array}$ \\
\hline Makespan & $\begin{array}{l}\text { Represents the time of completion of patient recovery. It generally can } \\
\text { be defined as the time between the entry of the first patient and the } \\
\text { completion of the last patient. }\end{array}$ \\
\hline Cancellations & $\begin{array}{l}\text { Number of canceled surgeries that result in idle capacity in the } \\
\text { schedules, low productivity, and increased waiting time for patients. }\end{array}$ \\
\hline Financial Results & $\begin{array}{l}\text { Performance measures related to cost and financial gains that the OR } \\
\text { refers to the hospital system. }\end{array}$ \\
\hline Preferences & $\begin{array}{l}\text { Analyzes the preferences of the different parties involved in the surgical } \\
\text { process, such as preferences of surgeons, nursing staff, patients, etc. }\end{array}$ \\
\hline
\end{tabular}

In terms of measuring the performance of ORs, Mazzei (1994) provided the first published data for start-up times and set-up times for surgery in a teaching hospital. According to the author, patients for the first surgery of the day were generally taken to the operating room, the incision occurred between 21 and 49 minutes later, and the room set-up time took approximately one hour. It is observed that, 20 years ago, the author was studying opportunities to reduce start-up times and set-up times. According to the author, standardizations for these times should be agreed upon by the interdisciplinary areas, and constant measurements should be taken.

Dexter et al. (2003) considered the times of an OR of a tertiary hospital with four operating rooms. The study was conducted in 2001. The average set-up time for a room was estimated to be between 34 and 66 minutes. Reductions in the average set-up time of 3-9 minutes resulted in a reduction of between $0.8 \%$ and $1.8 \%$ of personnel costs, without affecting the level of service or production of surgeries. This reduction was estimated as savings of between US\$52,000 and US\$151,000, while considering only costs with staff and anesthesia in the four operating rooms studied. A projected reduction in the average set-up time of 10-19 minutes would lead to a reduction of $2.5 \%$ to $4.0 \%$ in personnel costs, representing an annual operating income of US\$151,000 to US\$243,000. Therefore, according to the study, even small improvements can represent substantial gains when placed in a sustainable and long-term perspective. 
Based on the arguments presented, mainly regarding the performance measures set out in Table 1, we observe that the time dimension may be used as the primary metric for tracking and signaling OR efficiency because the use of the rooms is related to the time used and scheduled; surgical cancellations relate to operating room downtime after the cancellation; the yield or production of the rooms can be analyzed from the perspective of time, based on the available time for surgeries and use, such that the greater the use is, the higher the yield and the lower the waiting time for patients; makespan is also related to time, from the entry of the first patient to the exit of the last; and finally, the financial results can also be analyzed as the cost per hour of the operating room, causing non-working hours to be eliminated for better asset utilization. However, their use may be more effective if supported by specific assumptions, such as programming, use, preparation, and others studied in the surgical process, as shown in the next section. A vision guided by the surgical process is necessary to create a global indicator for operating room effectiveness.

\section{METHODOLOGY}

The present study has an exploratory, descriptive, and applied nature. It is exploratory because it approaches concepts regarding management in the healthcare operations environment, and it is descriptive because it narrates the application implemented in the specific context of the university hospital studied. The main steps for developing the study are presented in Table 2 and explained in the sequence.

Table 2 - Steps for the development of the approach

\begin{tabular}{|l|}
\hline 1. Bibliographical Reference \\
\hline 2. Direct Observation and Interviews \\
\hline 3. Analyses and Proposition of the Indicator \\
\hline 4. Application Study \\
\hline 5. Evaluation by Committee \\
\hline 6. Validation of Indicator \\
\hline 7. Creation of Hypothetical Scenarios \\
\hline
\end{tabular}

The study began with the construction of a bibliographical analysis about losses and performance in operating rooms. A search in the database SCOPUS about "operating rooms" and "performance indicator" and "Lean" resulted in only one study relating the subjects studied. 
Hassanain et al. (2017) evaluated the intervention on the performance of operating rooms using the Lean methodology and performance measures different from the proposal presented by this study.

Given the lack of published evidence, a study was conducted in public and private hospitals in southern Brazil, collecting information on the OR management process of these hospitals through direct observation and interviews. The choice of hospitals was made based on convenience, and not only geographically, given that a certain level of trust is required between the researcher and the hospital to allow access to areas with high sanitary control. Thirty nine employees from different areas of these hospitals were interviewed during four months. All had at least 10 years of experience in the process or in fields directly related to the OR. The structure of the interviews followed the protocol of open interviews, which were conducted with exploratory purpose. The objective was to refine concepts (e.g. types of operational wastes) related to the effectiveness of operating rooms, to support the adaptation of the OEE indicator based on the qualitative information collected. The content of the interviews was compiled to generate categories of losses. The results and the benchmarks were analyzed to organize the proposed effectiveness indicator.

After the indicator was proposed, an application study was conducted in the same hospital and the application occurred during six months. Initially, the researchers collected 10 months of the OR's operation historical data from the organization's information system, in order to analyze the effectiveness of the indicator. With the data compiled and adjusted, a committee was formed with seven experts from the organization, including engineers, surgeons, and members of senior management, to evaluate the results. The committee evaluated the results, audited the calculation procedure used, and considered it valid. Then, the researchers proceeded to implement the data collection processes and monitor the proposed indicator in the organization, seeking a longitudinal analysis of the information produced by the indicator. Finally, the indicator was presented and validated for use in the hospital organization studied. Within this paper scope, researchers developed hypothetical scenarios with the data collected to explore possible improvements and action plans for the study hospital or others to apply using the proposed ORE indicator.

\section{OPERATING ROOM EFFECTIVENESS (ORE)}

OEE can be defined as an overall effectiveness indicator of a production facility or equipment (Gibbons and Burgess, 2010). This indicator had its origin in Total Productive 
Maintenance (TPM), whose methodology aims to reach a compromise with all entities of an organization to integrate them, improve quality, and increase the productivity and effectiveness of the production system (Nakajima, 1998; Ivancic, 1998; Jain, Bhatti and Singh, 2014). TPM is regarded as one of the pillars of Lean Manufacturing due to the goal of eliminating waste by optimizing resource effectiveness (Sahoo and Yadav, 2018). It is also viewed as a method of measuring production performance that integrates data on equipment availability, performance indicator, and the quality rate achieved (Belohlavek, 2006).

OEE is calculated by identifying six basic types of losses grouped into three classes presented in Table 3.

Table 3 - Six basic losses by OEE (Nakajima, 1998; Ivancic, 1998; Busso and Miyake, 2013)

\begin{tabular}{|c|c|}
\hline Classes & Losses \\
\hline \multirow{2}{*}{ Availability Losses } & downtime for lack of equipment \\
\cline { 2 - 2 } Performance Losses & downtime for setup or adjustments \\
\cline { 2 - 2 } Quality Losses & short breaks for poor equipment operation \\
\cline { 2 - 2 } & reduction in equipment speed \\
\hline \multirow{2}{*}{ losses incurred at the start of production due to adjustments } \\
for equipment stabilization
\end{tabular}

According to Nakajima (1998), these basic losses guide actions for improvement, given that the analysis of the component values allows us to identify where the weaknesses in the effectiveness of the production system are located. An interpretation of losses found in a healthcare system may be given by Vaccaro et al. (2015), reinforcing the importance of the classification above.

Using the OEE indicator and its consequences as a foundation, the present study makes an adaptation of the indicator to the Operating Rooms Effectiveness (ORE), for application in the OR in Lean Healthcare context. The main difference between OEE and ORE is the focus on the surgical flow and its specificities. Considering these specificities, the ORE presents seven types of losses. The proposed indicator maintains the classes proposed by Nakajima (1998) to maintain simplicity and compatibility with the existing interpretation of OEE. However, ORE presents a reinterpretation of the losses associated with each class that is consistent with the nature of operating room processes. The reference proposed by Nakajima (1998) of "heavy losses" is also maintained due to similarity in interpretation. Figure 1 presents the proposed calculation and perspectives of analysis for the proposed indicator.

Similar to the OEE, the ORE can be obtained by the product of the Availability, Performance, and Quality indicators or the ratio between the Total Time of Added Value 
(TTAV) and Total Time Available (TTA) measures. Each indicator, shown at the right, is a fraction of time, and the numerators are smaller than or equal to the denominator because the times corresponding to losses are taken from here.

Availability is closely linked to the time available for the operating room's production and its operating time. It comes from Total Time Available, defined by managers and medical staff as the time destined for surgeries. It is typically associated with the time that teams of surgeons, nurses, and anesthetists are available.

Figure 1 - Operating Room Variables and Losses (inspired on Nakajima, 1998)

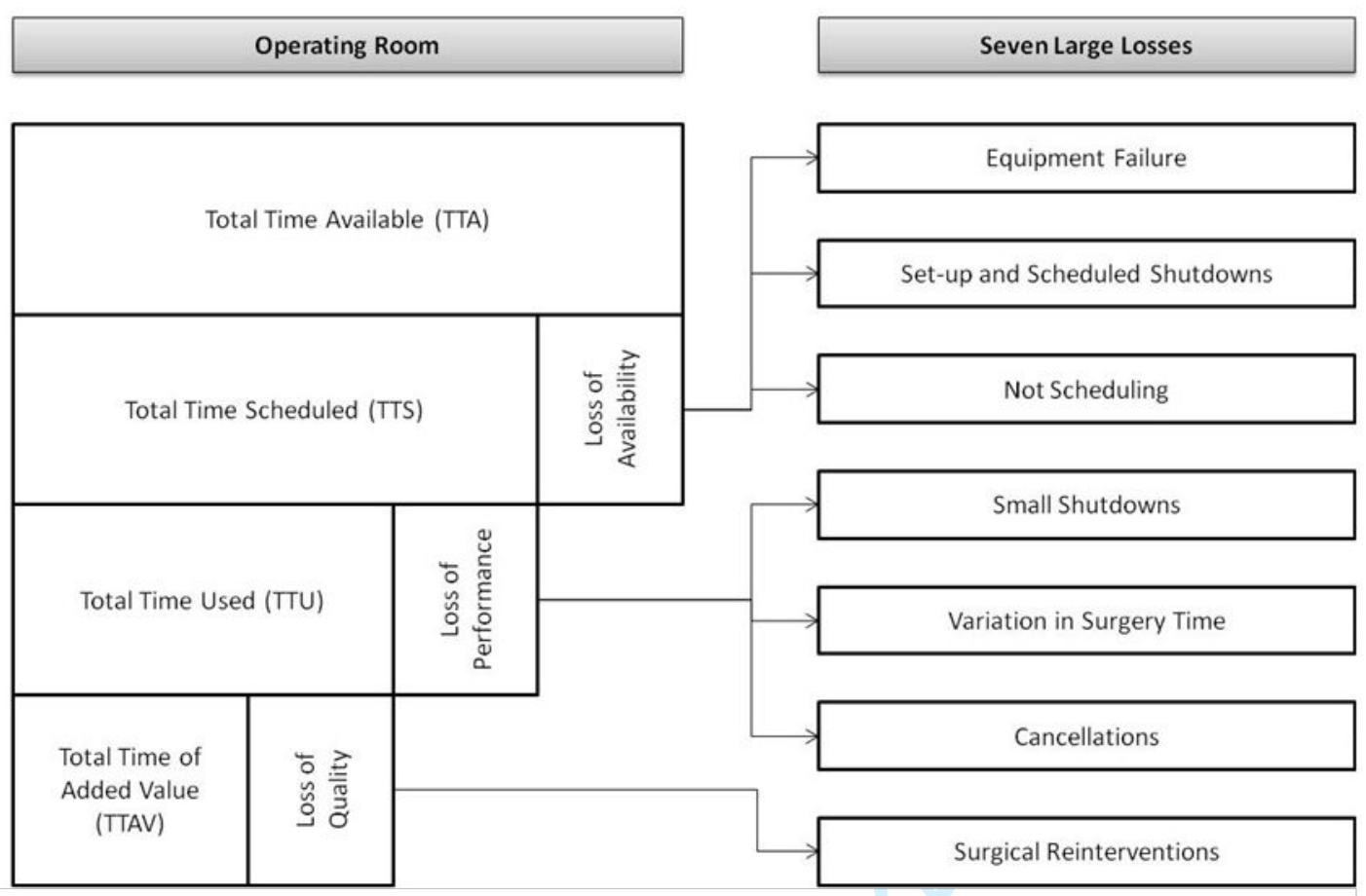

To calculate the room's availability index, we subtract from the Total Time Available (TTA), the time lost due to planned shutdowns for maintenance (equipment failure); set-ups (room preparation and cleaning); and idleness due to not scheduled surgeries. The latter loss is observed in university and public hospitals and can be due to schedule management: surgeons have pre-allocated time shifts to perform the procedures under their responsibility, regardless of whether these procedures occur. The incomplete use of these shifts may cause losses because the other team cannot use the reserved room. The net time is referred to as the Total Time Scheduled (TTS). 


$$
\text { Availability }=\frac{\text { Total Time Scheduled }(\text { TTS })}{\text { Total Time Available }(\text { TTA) }}
$$

The operating room's Performance is measured as the fraction of the TTS that is not lost with variations from the previously made schedule. These variations include short shutdowns (problems with equipment, surgical supplies, momentary power outages, etc.); complications related to the procedure or the patient's clinical situation that are only identified during surgery, exceeding the planned time; and cancellations of surgeries. The resulting time is referred to as the Total Time Used (TTU).

$$
\text { Performance }=\frac{\text { Total Time Used }(T T U)}{\text { Total Time Scheduled (TTS) }}
$$

Finally, the Quality Index is measured as the fraction of the TTU that is not lost on surgical interventions, error, or failure in the surgical procedure. The net time is called the Total Time of Added Value (TTAV).

$$
\text { Quality }=\frac{\text { Total Time of Added Value (TTAV) }}{\text { Total Time Used (TTU) }}
$$

When interpreting the nature of the losses that exist in the OR, this indicator approaches the operational reality of surgical service management. Cima (2011) states that the analysis of efficiency and effectiveness is essential for operating room management. Demeulemeester et al. (2013) proposes eight performance measures for the managerial analysis of the operating room process, but each indicator is analyzed separately in the system. Therefore, the present study proposes a combination of the performance measures related to the timing of operating rooms with an integrated analysis of efficiency, effectiveness and signaling the losses. The next section illustrates the application of the ORE in the hospital that participated in this study and presents the data for the tests.

\section{APPLICATION, ANALYSIS, AND DISCUSSION}

The hospital organization providing the data for the implementation of the proposed indicator is a large university hospital run by public-private management. It is located in 
southern Brazil. It has 500 inpatient beds, an outpatient facility with approximately 11,000 consultations per month, 7,000 surgeries per year, and a Diagnostic Center and Laboratory for up to 72,000 tests per month.

The OR under study initially consisted of seven operating rooms divided to meet various specialties: Oral and Maxillofacial, Cardiovascular Surgery, Digestive Surgery, General Surgery, Pediatric Surgery, Plastic Surgery, Thoracic Surgery, Vascular Surgery, Coloproctology, Gastroenterology, Gynecology, Neurosurgery, Traumatology, Otolaryngology, and Urology. The scheduled availability of the operating rooms included the period from 07:30 to 19:00. In this period, elective and urgent surgeries were performed based on surgical scheduling, which was divided into two daily shifts.

The study analyzed 10 months the performance of the surgical center of the study hospital and the monthly values of ORE are presented in Figure 2, using the calculation of the indicator proposed in Figure 1. In aggregate, with an average effectiveness of 57\% and seven operating rooms, the study unit conducted an average of 600 surgeries/month. There was an effectiveness gain between the months of December (51\%) and May (63\%), followed by a low after the month of July (53\%). The drop was related to a lack of anesthetists caused by the reduction in government transfers, reducing the productive capacity of the system and thereby the effectiveness as a whole. As stated above, the operating room capacity is based on strong coupling between physical infrastructure, supplies, and personnel. Reducing the number of anesthesiologists had a strong impact on the cancellations of surgeries, and even with doctors, nurses, rooms, and demand for surgeries, the procedures could not be performed.

Figure 2 - Monthly Monitoring of ORE

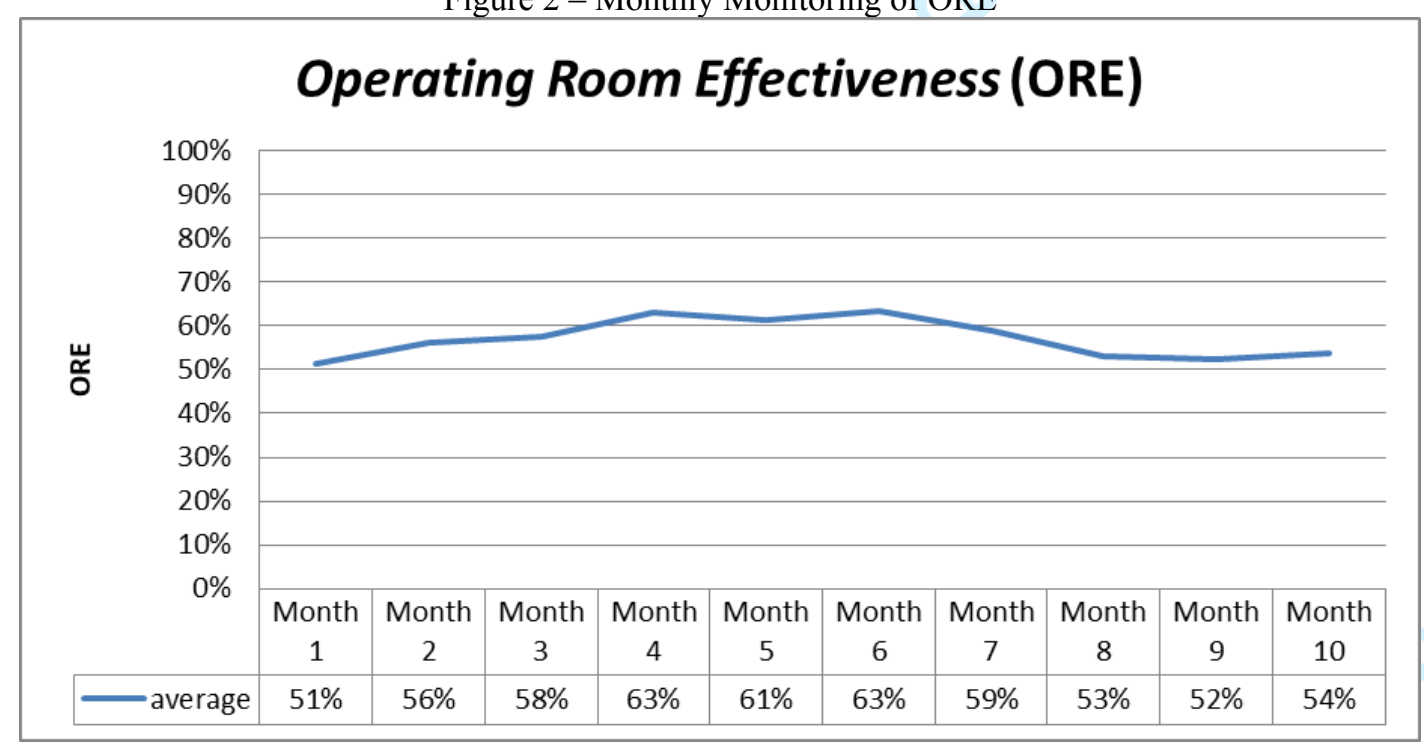


An analysis of the impacts and causes of inefficiency was performed, and this article only presents the analysis based on the average value of the effectiveness identified $(57.3 \%)$ in the collection period. An accurate month-to-month analysis was conducted but will not be shown to protect the organization's most specific data and characteristics.

Figure 3 illustrates the number of hours distributed for each monitored variable. On average, the hospital studied lost 346 hours of monthly availability. A more detailed analysis revealed that 269 hours were associated with set-up (room cleaning and preparation time, with a standard time of 30 minutes per procedure) and 77 hours due to no scheduled surgeries. As a result, the availability rate obtained was $72.6 \%$ (919 hours/1,265 hours). It is noteworthy that, on average, $6.08 \%$ of the available time was lost due to the management policy adopted by the hospital, with shifts for surgeons regardless of their actual demand and flawed control regarding the use of rooms for each surgeon. On average, the 77 hours lost were due to idleness resulting from the surgeons' shifts not having a full schedule, an exclusively managerial decision.

Figure 3 - Time Used to Calculate ORE

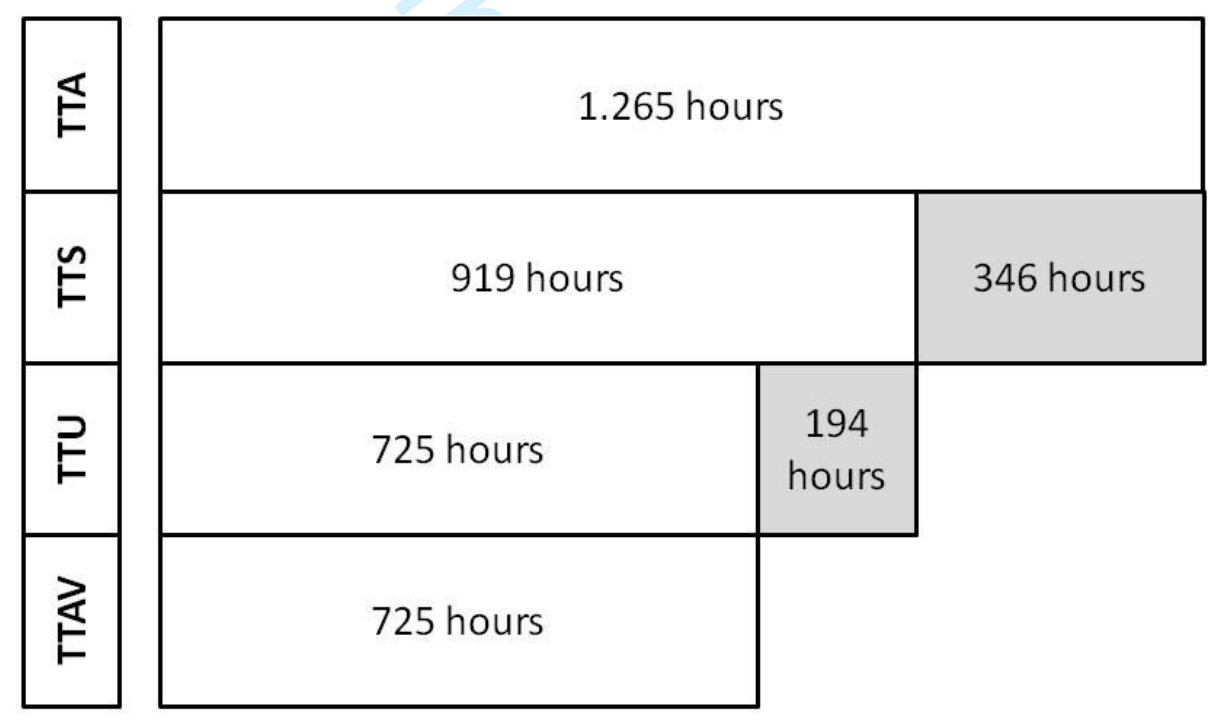

Total Time Available (TTA), Total Time Scheduled (TTS), Total Time Used (TTU), Total Time of Added Value (TTAV).

From the average of 725 hours spent, average performance losses of 194 hours were observed, resulting in a performance index of 78.9\%. The details of these losses revealed 151 hours lost due to surgery cancellations and 43 hours due to the variability of surgical time, i.e., the time used was less than that scheduled. The analysis of these causes needs to be detailed, given that surgeries that take more time than expected may lead to subsequent cancellations. To show the impact of this interdependence, we sought data on cancellations. The average surgery cancellations during the listed months were $18 \%$ of the surgeries scheduled, i.e., 
approximately 100 canceled surgeries/month (Figure 4). The stratification of the reasons indicated the following: a lack of clinical condition of the patient $(30 \%)$, patient absenteeism $(20 \%)$, greater time spent on the previous surgery (14\%), emergency fittings $(7 \%)$, and several others with less frequency $(29 \%)$.

It is noteworthy that $50 \%$ of cancellations occur due to the lack of medical condition or absenteeism of the patient. Based on an analysis of the literature, this fact can be a result of the flawed management of the preoperative patient flow, such as errors in scheduling, wrong information delivered to the patient, a lack of scheduling pre-operative tests, and pre-anesthetic ratings (Pires, 2010; Laganga, 2011; Lemos et al., 2013).

Figure 4 - Monthly Monitoring of Surgical Cancellations

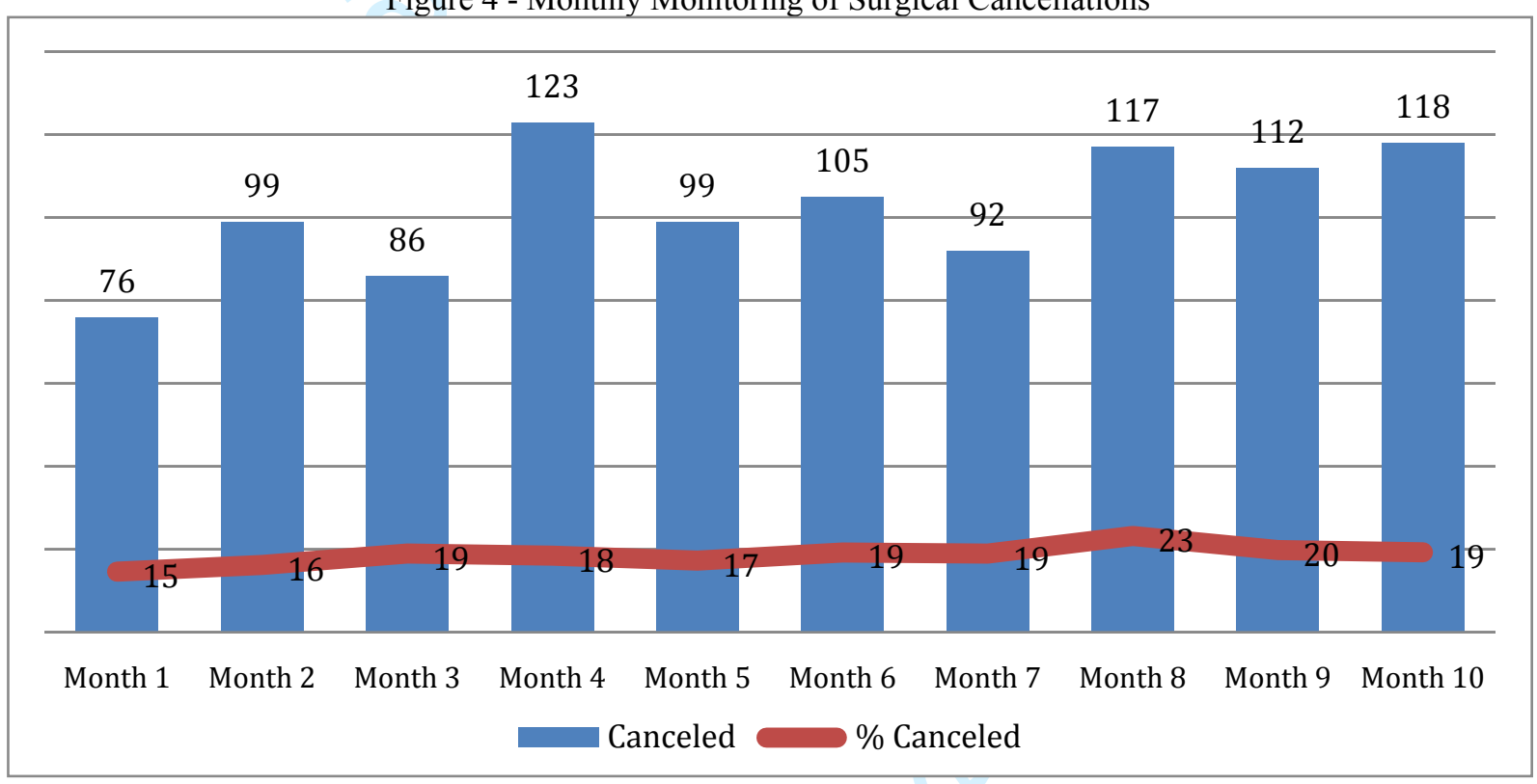

With respect to the TTAV, the present study considered that the time related to losses due to quality was 0 (zero). This decision was due to the lack of consistent data on surgical reinterventions or other technical data associated with surgical failure. Thus, the quality index was found to be $100 \%$, a conservative estimate, yet knowingly overestimated according to the hospital collaborators.

Therefore, based on the collected data for time, the average effectiveness of the operating room evaluated by the proposed indicator in this situation is $57.3 \%(=72.6 \% \times 78.9 \%$ x $100 \%$ or 725 hours/1265 hours). In objective terms, this analysis indicates that over $40 \%$ of the nominal time provided by the OR is lost due to various reasons. Some of these reasons, such as the patient's clinical condition (Cima et al., 2011), cannot be controlled, but most of the losses found can be managed and controlled through performance indicators and critical 
analyses, in addition to integrated scheduling sectors to improve the flow of patients and information to the medical staff.

It can be seen in the application of the indicator, according to Figure 1 where the ORE calculation is presented, that there are losses in both Availability and Performance, since Quality was maintained at $100 \%$. Among the losses by Availability, it is synthetically visualized Setup, Scheduled Shutdowns and Not Scheduling. Among performance losses, a high percentage of Cancellations and Variation in Surgery Time can be verified.

To illustrate the effects associated with ORE and its aim for improvements, some scenarios are derived in Table 4. The scenarios presented are hypothetical and show the usability of the ORE indicator, which is to guide actions with a focus on effectiveness. Seven hypothetical scenarios are suggested to highlight possible improvements in the process and to therefore increase the ORE of operating rooms. We also present a variation compared with the times collected in the hospital under study and the gain in hours with such improvements.

The focus of the scenarios is related to the losses found by the application of the ORE indicator presented in the literature and pervades improvements in "No Scheduling", "Reduction in Set-up", and "Reduction in Cancellations".

The first scenario (A) proposes an optimization of scheduling operations in the surgeons' shifts, and all scheduled surgeries should fit exactly in the total time available; therefore, no scheduling is close to 0 (zero). Thus, ORE increases by $6.1 \%$, although we know it is difficult to fit surgeries exactly in shifts due to differences in the procedures in line and their different completion times. However, further analysis and knowledge of these factors when scheduling are suggested. The second scenario (B) is associated with reducing the set-up time or obtaining optimized room set-up and cleaning. With this redesign, the ORE may have a $3.5 \%$ increase and an additional 44.8 hours. There is a limitation in this item related to the number of employees in the cleaning and preparation process, in addition to material handling. These variables should be analyzed for application. The third scenario (C) aims to reduce nonscheduling by half, given the complexity of the perfect fit of surgeries in shifts and the reduction of five minutes in the set-up. With this scenario, ORE will increase by $6.6 \%$ or 83.3 hours.

Another important factor to be considered is the cancellation of surgeries, which leaves rooms idle. Scenario D indicates a $20 \%$ reduction in cancellations, mainly focusing on absenteeism and variations in the time used and time planned. With the creation of control mechanisms, this variable can achieve a gain of $2.4 \%$ in the ORE and an additional 30.2 hours. Scenario E proposes a combination of scenarios A and D, but we already know the difficulties with not-scheduling close to zero. Nevertheless, the analysis indicates a gain of $8.5 \%$ of ORE 
and 107.2 hours. Scenario F differs from the previous in the reduction of cancellations, and in this scenario, the proposal is to reach $50 \%$ of them. Thus, the impact would be a $12.1 \%$ gain in ORE and 152.5 additional hours.

Finally, the last scenario $(G)$ for potential improvements in ORE presents a change in the management of the operation process and the highest gain, with a $31.6 \%$ increase in ORE and an additional 399.8 hours to perform surgeries. Although very difficult to achieve, this scenario should be analyzed and adapted, and it may be developed piecemeal over the longterm.

Noted that incremental improvements in the process, whether separate or integrated, directly impact the rates of Availability, Performance, and Quality, thus changing the overall indicator of ORE and adding hours to the operating room's production. It is noteworthy that the hypothetical improvements indicated are related to the problems found in the hospital under study and that equivalent simulations should analyze the situation in each operating room analyzed.

Table 4 - Impact of potential improvements on ORE

\begin{tabular}{|c|c|c|c|c|c|c|c|c|c|c|}
\hline Scenario & TTA & TTS & TTU & TTAV & Availability & Performance & Quality & ORE & $\begin{array}{c}\text { Variation } \\
\text { from the } \\
\text { Base }\end{array}$ & $\begin{array}{c}\text { Additional } \\
\text { Hours }\end{array}$ \\
\hline Base & 1265 & 919.0 & 725.0 & 725.0 & $72.6 \%$ & $78.9 \%$ & $100.0 \%$ & $\mathbf{5 7 . 3 \%}$ & $0.0 \%$ & 0.0 \\
\hline $\mathrm{A} * 1$ & 1265 & 996.0 & 802.0 & 802.0 & $78.7 \%$ & $80.5 \%$ & $100.0 \%$ & $\mathbf{6 3 . 4 \%}$ & $6.1 \%$ & 77.0 \\
\hline $\mathrm{B} * 2$ & 1265 & 963.8 & 769.8 & 769.8 & $76.2 \%$ & $79.9 \%$ & $100.0 \%$ & $\mathbf{6 0 . 9 \%}$ & $3.5 \%$ & 44.8 \\
\hline $\mathrm{C} * 3$ & 1265 & 1002.3 & 808.3 & 808.3 & $79.2 \%$ & $80.6 \%$ & $100.0 \%$ & $\mathbf{6 3 . 9} \%$ & $6.6 \%$ & 83.3 \\
\hline $\mathrm{D} * 4$ & 1265 & 919.0 & 755.2 & 755.2 & $72.6 \%$ & $82.2 \%$ & $100.0 \%$ & $\mathbf{5 9 . 7 \%}$ & $2.4 \%$ & 30.2 \\
\hline $\mathrm{E} * 5$ & 1265 & 996.0 & 832.2 & 832.2 & $78.7 \%$ & $83.6 \%$ & $100.0 \%$ & $\mathbf{6 5 . 8 \%}$ & $8.5 \%$ & 107.2 \\
\hline $\mathrm{F} * 6$ & 1265 & 996.0 & 877.5 & 877.5 & $78.7 \%$ & $88.1 \%$ & $100.0 \%$ & $\mathbf{6 9 . 4 \%}$ & $12.1 \%$ & 152.5 \\
\hline $\mathrm{G} * 7$ & 1265 & 1243.3 & 1124.8 & 1124.8 & $98.3 \%$ & $90.5 \%$ & $100.0 \%$ & $\mathbf{8 8 . 9} \%$ & $31.6 \%$ & 399.8 \\
\hline
\end{tabular}

Improvements: ${ }^{* 1}$ No scheduling $=0 .{ }^{* 2} 5$-minute reduction in set-up. ${ }^{* 3}$ No scheduling reduced to half and 5-minute reduction in set-up. ${ }^{* 4} 20 \%$ reduction in cancellations. ${ }^{* 5}$ No scheduling $=0$ and $20 \%$ reduction in cancellations. ${ }^{* 6}$ No scheduling $=0$ and $50 \%$ reduction in cancellations. ${ }^{* 7}$ No scheduling $=0,5$-minute reduction in set-up, and $50 \%$ reduction in cancellations

\section{FINAL CONSIDERATIONS}

Much of the knowledge acquired in the field of operations management originated in manufacturing, and it can be applied to service operations (Johnston, 1994). Problems in operations management that arise in healthcare are often similar to traditional problems in operations management. Managers of healthcare systems must manage inventory, measure and manage performance and system quality, and evaluate the performance of critical processes 
(Brandeau et al., 2004). These issues are discussed in the application of Lean Management in hospitals, called Lean Healthcare. With focus on reducing wastes and improving flow, Lean Healthcare becomes necessary when discussing Operating Rooms. For, it is necessary to optimize the surgical flow increasing the effectiveness of the operating rooms and reducing the losses found.

The present article contributes to the field of health operations management in that it proposes a perspective for OR effectiveness that is guided by concepts recognized in the context of lean and operations management. Based on the appointment and analysis of process times and, above all, the typical losses of an OR, the study proposes an adaptation of the OEE indicator (Nakajima, 1998), called ORE (Operating Room Effectiveness), for the healthcare scenario. An application based on data from a Brazilian university hospital currently using this concept is presented, in addition to a set of scenarios for analysis created to illustrate how managers can use the indicator to determine action plans with an emphasis on increasing the ORE.

The application shows that, of the 1,265 monthly hours allocated for operations in the organization studied, only 725 are effectively converted into value for the patient. This figure is optimistic, considering that data on re-interventions do not exist and cannot be incorporated into the analysis. For the indicator, $27.4 \%$ (346 hours) were losses of availability related to the set-up time of the rooms and no scheduling (idleness), and 15.3\% (194 hours) were identified as performance losses related to the time of canceled surgeries and less time scheduled than used. The use of the indicator by the organization showed the path to improvements in plans previously implemented by various measurements and without a focus on effectiveness.

The ORE indicator proposed by this study allow an integrated view of the performance of the OR, as opposed to the majority of other studies that present other performance indicators as Waiting time, Throughput, Utilization, Leveling, Makespan, Cancellations, Financial Results and Preferences presented by Demeulemeester et al. (2013). The analysis of OR losses supported by the OEE indicator allow a global view of the overall performance of the ORs rather than a partial view based on the analysis of each indicator referred by Demeulemeester et al. (2013). Therefore, with the application in a hospital OR, a validation of the ORE as an adaptation from OEE (Nakajima, 1998; Ivancic, 1998; Gibbons and Burgess, 2010; Busso and Miyake, 2013) was verified, contributing to the analysis of effectiveness in ORs in hospital environments.

This study is an exploratory study; it only proposes and applies an indicator for an OR. Although guided by theoretical and conceptual references, the definition of the types of losses 
and their association with the ORE indices is also based on the observation of real environments limited to the south of Brazil. It is understood that mimetic isomorphism (Dimaggio and Powell, 2000) between hospital environments contributes to the applicability of the proposed indicator, but further studies and applications must be performed.

As reported by Kodali et al. (2014), there are obstacles in managing changes in health organizations, such as the organizational culture of leaders, managers, and agents of change in healthcare organizations. The awareness of the many variables that can support or hinder a particular effort to change can inform implementation strategies for effective improvements that are compatible with the DNA of the organization. In the present study, obstacles, such as the fear of applying techniques from industry in the healthcare process, the acceptance of the medical and nursing staff in measuring and scheduling time, and the implementation of improvements that break the existing barriers in the organization, were encountered. However, with the presentation of the collected data, the average ORE of the hospital under study, and the impact of the scenarios on the overall indicator, some barriers were overcome with the understanding of the scientific method.

We suggest future research on the application of the proposed indicator in other health institutions and a further discussion of the concepts of Quality and Added Value in operating times, mainly with technical healthcare concepts due to the limitation in obtaining data on surgical re-interventions in the organization, in addition to a technical discussion about how many re-interventions are due to flaws and how many are not. Another research suggestion is related to programming and leveling the productive capacity of an OR to analyze the overall patient flow and the behavior of surgery waiting lines.

\section{ACKNOWLEDGEMENTS}

This work was partially supported by Portuguese national funds through FCT - Fundação para a Ciência e Tecnologia within the Project Scope: UID/CEC/00319/2019.

\section{REFERENCES}

Abu Bakar, F. A., Subari, K., and Mohd Daril, M. A. (2015), "Critical success factors of Lean Six Sigma deployment: a current review”, International Journal of Lean Six Sigma, Vol. 6 No. 4, pp. 339-348.

Belohlavek, P. (2006), OEE: overall equipment effectiveness, Blue Eagle Group, Buenos Aires.

Busso, C. and Miyake, D. (2013), "Análise da aplicação de indicadores alternativos ao Overall Equipment Effectiveness (OEE) na gestão do desempenho global de uma fábrica", Production Journal, Vol. 23 No. 2, pp. 205-225.

Brandeau, M. L., Sainfort, F. and Pierskalla, W. P. (Eds.). (2004), Operations research and health care: a handbook of methods and applications (Vol. 70), Springer Science \& Business Media. 
Cardoen, B., Demeulemeester, E. and Beliën, J. (2010), “Operating room planning and scheduling: A literature review", European Journal of Operational Research, Vol. 201 No. 3, pp. 921-932.

Cima, R. R., Brown, M. J., Hebl, J. R., Moore, R., Rogers, J. C., Kollengode, A., ... \& Team, S. P. I. (2011), "Use of lean and six sigma methodology to improve operating room efficiency in a highvolume tertiary-care academic medical center", Journal of the American College of Surgeons, Vol. 213 No. 1, pp. 83-92.

Collar, R. M., Shuman, A. G., Feiner, S., McGonegal, A. K., Heidel, N., Duck, M., ... \& Bradford, C. R. (2012), "Lean management in academic surgery", Journal of the American College of Surgeons, Vol. 214 No. 6, pp. 928-936.

Demeulemeester, E., Beliën, J., Cardoen, B. and Samudra, M. (2013), “Operating room planning and scheduling”, In Denton, B.T. (Ed.), Handbook of healthcare operations management, Springer, New York, pp. 121-152.

Dexter, F., Abouleish, A. E., Epstein, R. H., Whitten, C. W. and Lubarsky, D. A. (2003), "Use of operating room information system data to predict the impact of reducing turnover times on staffing costs", Anesthesia \& Analgesia, Vol. 97 No. 4, pp. 1119-1126.

DiMaggio, P.J. and Powell, W.W. (2000), "The iron cage revisited institutional isomorphism and collective rationality in organizational fields", in Baum, J.A.C. \& Dobbin, F. (eds.), Economics Meets Sociology in Strategic Management - Advances in Strategic Management, Emerald Group Publishing Limited, pp. 143-166.

Gibbons, P. M. and Burgess, S. C. (2010), "Introducing OEE as a measure of lean Six Sigma capability", International Journal of Lean Six Sigma, Vol. 1 No. 2, pp. 134-156. doi:10.1108/20401461011049511

Graban, M. (2009), Lean hospitals: improving quality, patient safety, and employee satisfaction. CRC Press.

Hassanain, M., Zamakhshary, M., Farhat, G. and Al-Badr, A. (2017), "Use of Lean methodology to improve operating room efficiency in hospitals across the Kingdom of Saudi Arabia", The International journal of health planning and management, Vol. 32 No. 2, pp. 133-146.

Hopp, W. J. and Spearman, M. L. (2011), Factory physics. Waveland Press.

Ivancic, I. (1998), "Development of maintenance in modern production", In Euromaintenance'98 Conference Proceedings, Dubrovnik, Croatia, pp. 5-7.

Jain, A., Bhatti, R. and Singh, H. (2014), "Total productive maintenance (TPM) implementation practice: A literature review and directions", International Journal of Lean Six Sigma, Vol. 5 No. 3, pp. 293-323. doi:10.1108/IJLSS-06-2013-0032

Johnston, R. (1994), “Operations: from factory to service management", International Journal of Service Industry Management, Vol. 5 No. 1, pp. 49-63.

Kodali, B. S., Kim, D., Bleday, R., Flanagan, H. and Urman, R. D. (2014), "Successful strategies for the reduction of operating room turnover times in a tertiary care academic medical center", Journal of surgical research, Vol. 187 No. 2, pp. 403-411.

Marjamaa, R., Vakkuri, A. and Kirvelä, O. (2008), “Operating room management: why, how and by whom?”, Acta Anaesthesiologica Scandinavica, Vol. 52 No. 5, pp. 596-600.

Matern, U. and Koneczny, S. (2007), "Safety, hazards and ergonomics in the operating room", Surgical endoscopy, Vol. 21 No. 11, pp. 1965-1969.

Mazzei, W. J. (1994), “Operating room start times and turnover times in a university hospital”, Journal of clinical anesthesia, Vol. 6 No. 5, pp. 405-408.

Morilhas, L. J., Nascimento, P. T. S. and Fedichina, M. A. H. (2013), “Análise para a melhoria da gestão de operações na área hospitalar: um estudo a partir da utilização da filosofia lean healthcare" (in Portuguese), in Simpósio de Administração da Produção, Logística e Operações Internacionais XVI SIMPOI.

Nakajima, S. (1988), Introduction to TPM: Total Productive Maintenance. Productivity Press, Inc., 1988.

Narayanamurthy, G., Gurumurthy, A., Lankayil, A. A. and Narayanamurthy, G. (2018), "Experience of implementing lean thinking in an Indian healthcare institution", International Journal of Lean Six Sigma. Vol. ahead-of-print No. ahead-of-print. https://doi.org/10.1108/IJLSS-10-2016-0062

OECD (2013), "Health at a Glance 2013", available at: http://www.oecd.org/els/health-systems/Healthat-a-Glance-2013.pdf (accessed 12 May 2014. 
Raval, S. J., Kant, R. and Shankar, R. (2018), "Revealing research trends and themes in Lean Six Sigma: from 2000 to 2016", International Journal of Lean Six Sigma, Vol. 9 No. 3, pp. 399-443. doi:10.1108/IJLSS-03-2017-0021

Ribeiro, H. P. (1993), O hospital: história e crise (in Portuguese). Cortez Editora.

Sahoo, S. and Yadav, S. (2018), "Lean production practices and bundles: a comparative analysis", International Journal of Lean Six Sigma, Vol. 9 No. 3, pp. 374-398.

Shingo, S. (1989), A Study of the Toyota Production System: from an Industrial Engineering Viewpoint. Productivity Press.

Spagnol, C. A. and Ferraz, C. A. (2002), "Tendências e perspectivas da administração em enfermagem: um estudo na Santa Casa de Belo Horizonte-MG (in portuguese)", Revista Latino-Americana de Enfermagem, Vol. 10 No. 1, pp. 15-20.

Young, T. P. and McClean, S. I. (2008), "A critical look at Lean Thinking in healthcare", Quality and Safety in Health care, Vol. 17 No. 5, pp. 382-386.

Vaccaro, G. L. R., Azevedo, D., Vargas, D. F., Souza, T. A., Schlusen, M., Avila, L. and Kreutz, B. (2015), "Losses and Production Efficiency:an Interpretation for Critical Health Care Services", in Proceedings of the 2015 Industrial and Systems Engineering Research Conference, Nashville, USA.

Womack, J. P. and Jones, D. T. (2010), Lean thinking: banish waste and create wealth in your corporation. Simon and Schuster. 
Figure 1 - Operating Room Variables and Losses (inspired on Nakajima, 1998)

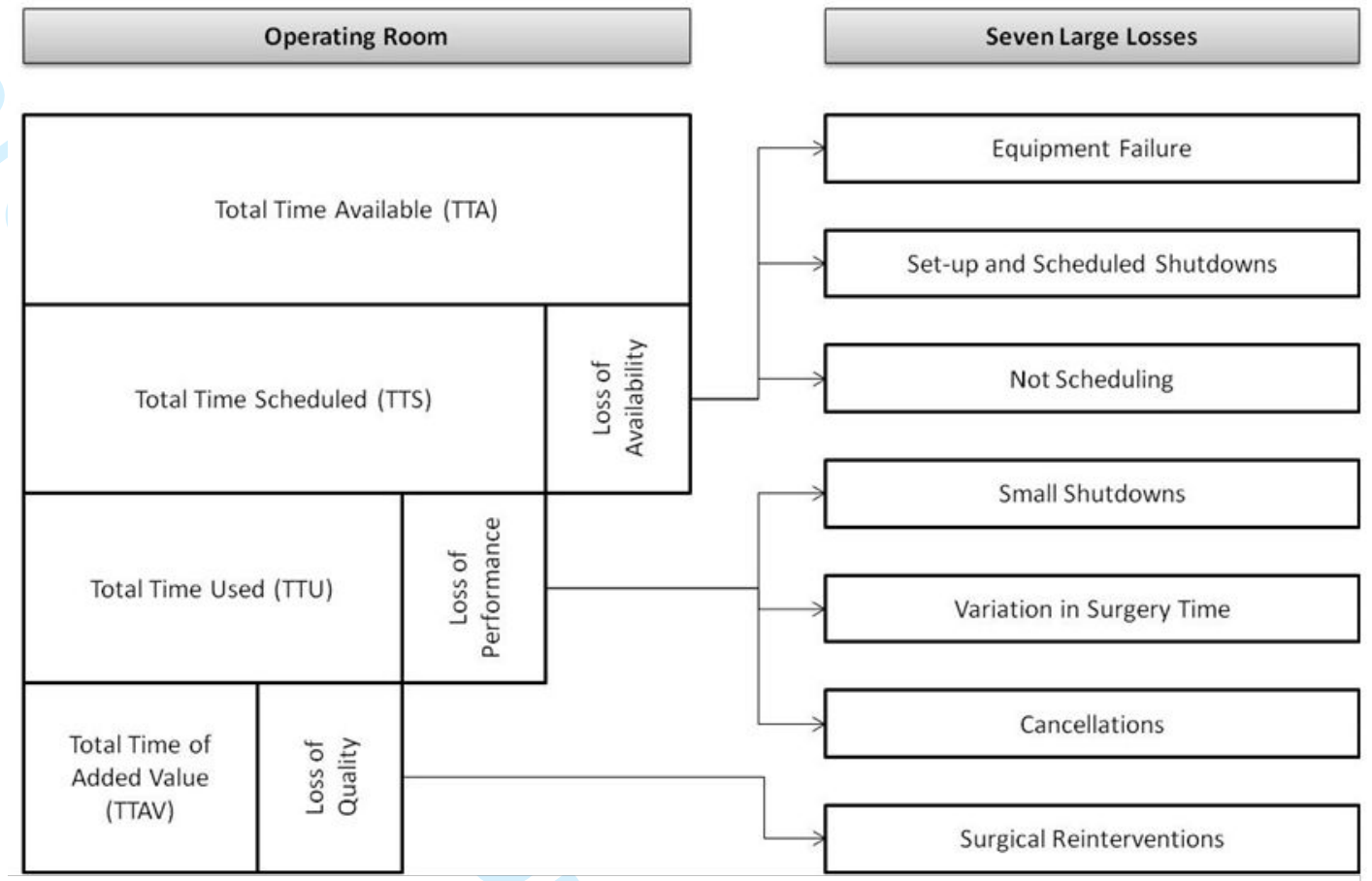

Figure 2 - Monthly Monitoring of ORE

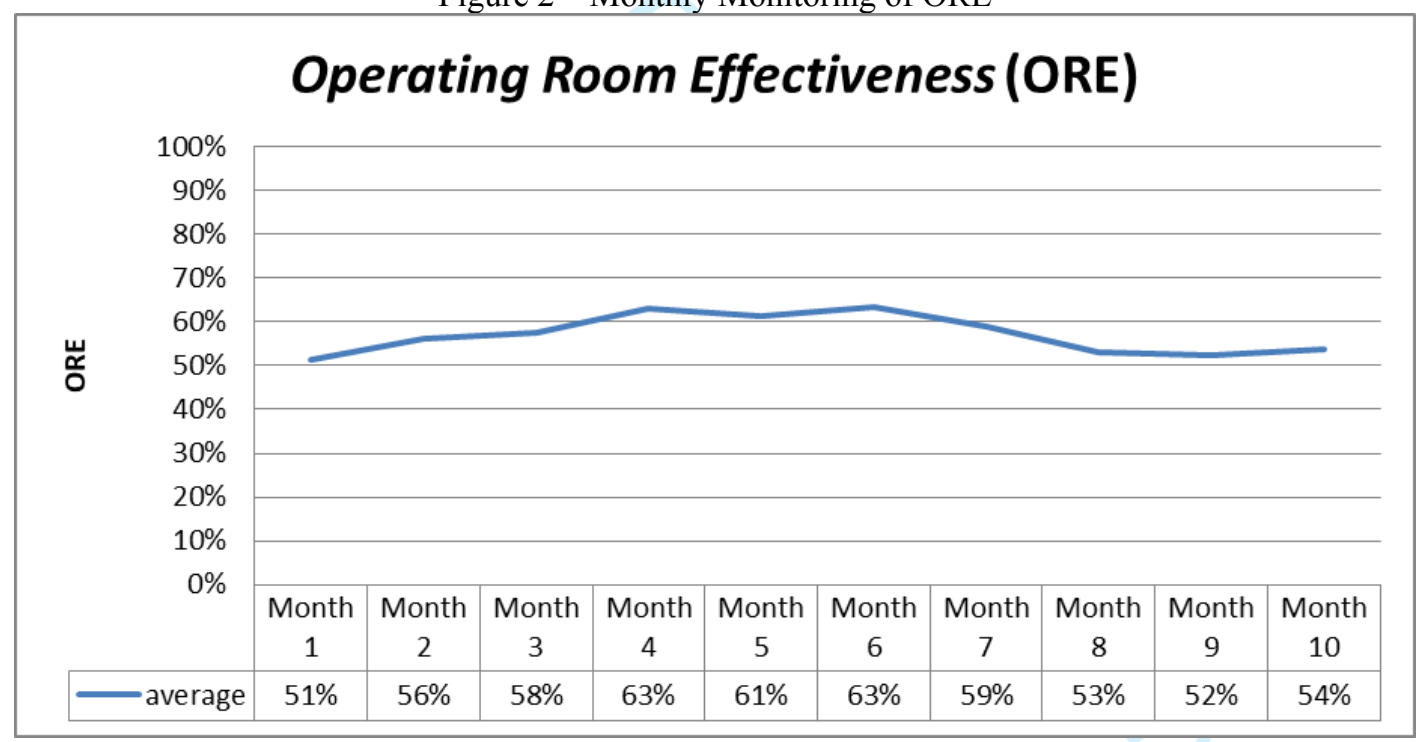


Figure 3 - Time Used to Calculate ORE

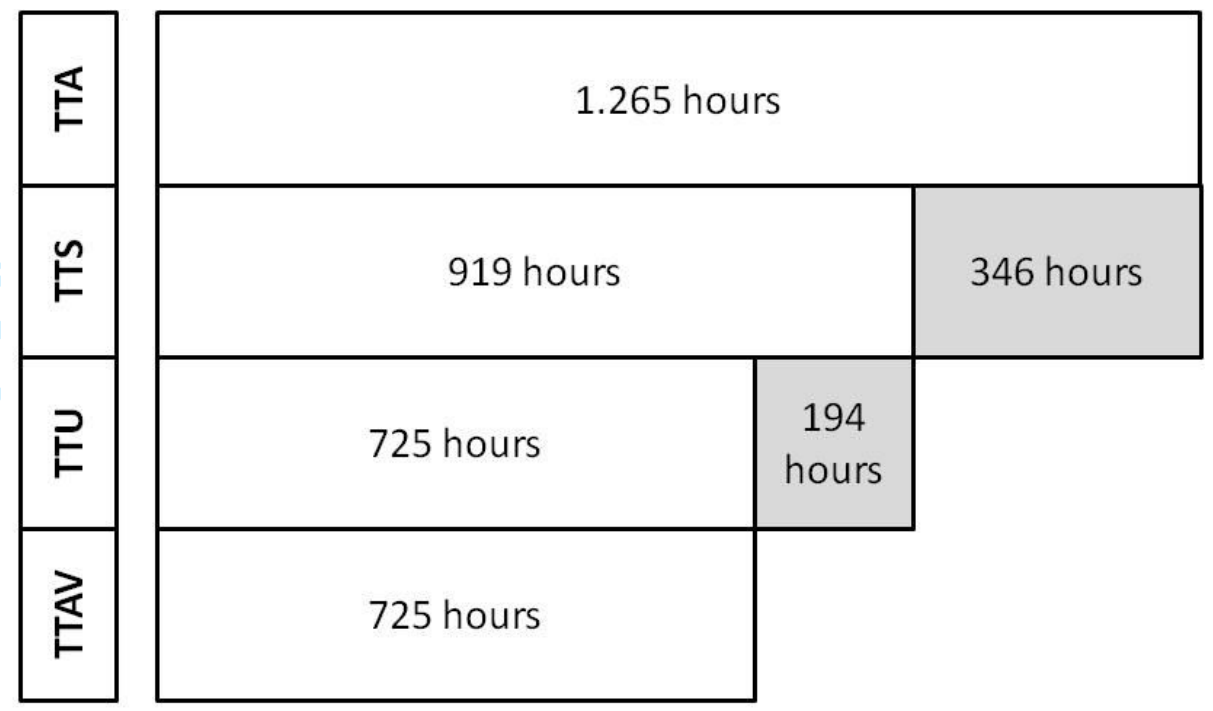

Total Time Available (TTA), Total Time Scheduled (TTS), Total Time Used (TTU), Total Time of Added Value (TTAV).

Figure 4 - Monthly Monitoring of Surgical Cancellations

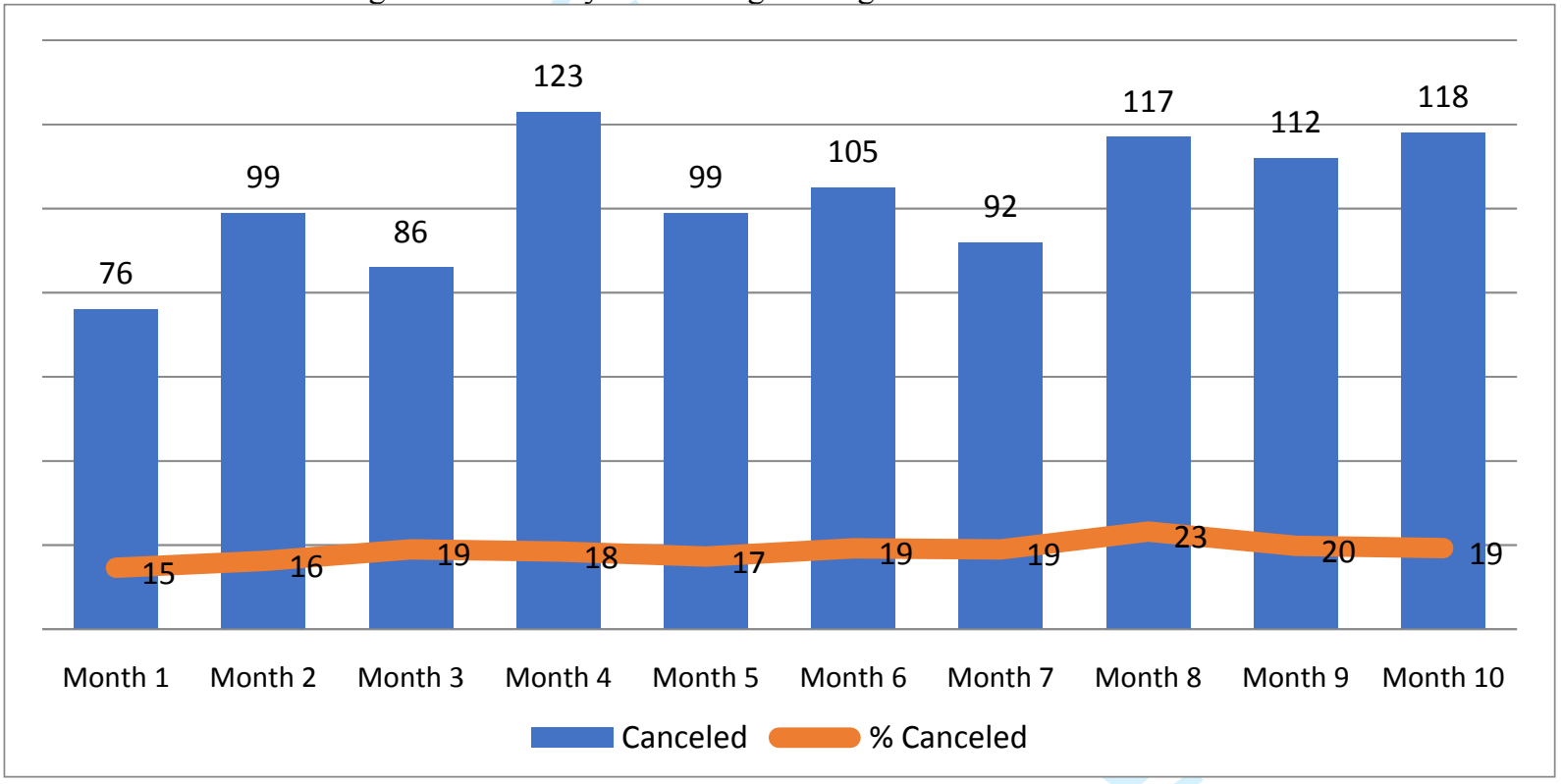


Table 1 - Performance Measures. Adapted from Demeulemeester et al. (2013)

\begin{tabular}{|c|l|}
\hline Performance Measures & \multicolumn{1}{c|}{ Description } \\
\hline Waiting time & $\begin{array}{l}\text { Represents the patient waiting time from the identification of surgical } \\
\text { needs to completion. }\end{array}$ \\
\hline Throughput & $\begin{array}{l}\text { Measurement related to the patient and waiting time, such that the } \\
\text { greater the yield of the operating rooms is, the shorter the patient waiting } \\
\text { time. }\end{array}$ \\
\hline Use & $\begin{array}{l}\text { Indicator related to the time spent using the operating room compared to } \\
\text { the scheduled time. The use does not take into account stops for } \\
\text { preparation and cleaning the rooms or scheduled stops. It only accounts } \\
\text { for the time used in relation to the time scheduled for production. }\end{array}$ \\
\hline Leveling & $\begin{array}{l}\text { Leveling concerns the development of operating room schedules that } \\
\text { lead to the smooth occupation of resources, without peaks and } \\
\text { minimizing the risk of capacity problems caused by unexpected events. }\end{array}$ \\
\hline Makespan & $\begin{array}{l}\text { Represents the time of completion of patient recovery. It generally can } \\
\text { be defined as the time between the entry of the first patient and the } \\
\text { completion of the last patient. }\end{array}$ \\
\hline Cancellations & $\begin{array}{l}\text { Number of canceled surgeries that result in idle capacity in the } \\
\text { schedules, low productivity, and increased waiting time for patients. }\end{array}$ \\
\hline Financial Results & $\begin{array}{l}\text { Performance measures related to cost and financial gains that the OR } \\
\text { refers to the hospital system. }\end{array}$ \\
\hline Preferences & $\begin{array}{l}\text { Analyzes the preferences of the different parties involved in the surgical } \\
\text { process, such as preferences of surgeons, nursing staff, patients, etc. }\end{array}$ \\
\hline
\end{tabular}

Table 2 - Steps for the development of the approach

\begin{tabular}{|l|}
\hline 1. Bibliographical Reference \\
\hline 2. Direct Observation and Interviews \\
\hline 3. Analyses and Proposition of the Indicator \\
\hline 4. Application Study \\
\hline 5. Evaluation by Committee \\
\hline 6. Validation of Indicator \\
\hline 7. Creation of Hypothetical Scenarios \\
\hline
\end{tabular}

Table 3 - Six basic losses by OEE (Nakajima, 1998; Ivancic, 1998; Busso and Miyake, 2013)

\begin{tabular}{|c|c|}
\hline Classes & Losses \\
\hline \multirow{2}{*}{ Availability Losses } & downtime for lack of equipment \\
\cline { 2 - 2 } Performance Losses & downtime for setup or adjustments \\
\cline { 2 - 2 } & short breaks for poor equipment operation \\
\hline \multirow{2}{*}{ Quality Losses } & reduction in equipment speed \\
\cline { 2 - 2 } & defective production and rework \\
\hline & $\begin{array}{c}\text { losses incurred at the start of production due to adjustments } \\
\text { for equipment stabilization }\end{array}$ \\
\hline
\end{tabular}


Table 4 - Impact of potential improvements on ORE

\begin{tabular}{|c|c|c|c|c|c|c|c|c|c|c|}
\hline Scenario & TTA & TTS & TTU & TTAV & Availability & $\begin{array}{c}\text { Performanc } \\
\text { e }\end{array}$ & Quality & $\begin{array}{c}\text { Oariation } \\
\text { Orom the } \\
\text { Base }\end{array}$ & $\begin{array}{c}\text { Additiona } \\
\text { 1 Hours }\end{array}$ \\
\hline Base & 1265 & 919.0 & 725.0 & 725.0 & $72.6 \%$ & $78.9 \%$ & $100.0 \%$ & $\mathbf{5 7 . 3 \%}$ & $0.0 \%$ & 0.0 \\
\hline $\mathrm{A} * 1$ & 1265 & 996.0 & 802.0 & 802.0 & $78.7 \%$ & $80.5 \%$ & $100.0 \%$ & $\mathbf{6 3 . 4 \%}$ & $6.1 \%$ & 77.0 \\
\hline $\mathrm{B} * 2$ & 1265 & 963.8 & 769.8 & 769.8 & $76.2 \%$ & $79.9 \%$ & $100.0 \%$ & $\mathbf{6 0 . 9} \%$ & $3.5 \%$ & 44.8 \\
\hline $\mathrm{C} * 3$ & 1265 & 1002.3 & 808.3 & 808.3 & $79.2 \%$ & $80.6 \%$ & $100.0 \%$ & $\mathbf{6 3 . 9} \%$ & $6.6 \%$ & 83.3 \\
\hline $\mathrm{D} * 4$ & 1265 & 919.0 & 755.2 & 755.2 & $72.6 \%$ & $82.2 \%$ & $100.0 \%$ & $\mathbf{5 9 . 7 \%}$ & $2.4 \%$ & 30.2 \\
\hline $\mathrm{E} * 5$ & 1265 & 996.0 & 832.2 & 832.2 & $78.7 \%$ & $83.6 \%$ & $100.0 \%$ & $\mathbf{6 5 . 8 \%}$ & $8.5 \%$ & 107.2 \\
\hline $\mathrm{F} * 6$ & 1265 & 996.0 & 877.5 & 877.5 & $78.7 \%$ & $88.1 \%$ & $100.0 \%$ & $\mathbf{6 9 . 4 \%}$ & $12.1 \%$ & 152.5 \\
\hline $\mathrm{G} * 7$ & 1265 & 1243.3 & 1124.8 & 1124.8 & $98.3 \%$ & $90.5 \%$ & $100.0 \%$ & $\mathbf{8 8 . 9 \%}$ & $31.6 \%$ & 399.8 \\
\hline
\end{tabular}

Improvements: ${ }^{* 1}$ No scheduling $=0 .{ }^{* 2} 5$-minute reduction in set-up. ${ }^{* 3}$ No scheduling reduced to half and 5-minute reduction in set-up. ${ }^{* 4} 20 \%$ reduction in cancellations. ${ }^{* 5}$ No scheduling $=0$ and $20 \%$ reduction in cancellations. ${ }^{* 6}$ No scheduling $=0$ and 50\% reduction in cancellations. ${ }^{* 7}$ No scheduling $=0,5$-minute reduction in set-up, and $50 \%$ reduction in cancellations 